\title{
The Benefits in Coupling Exergy Analysis and Life Cycle Assessment in the Context of Sustainable Manufacturing for Industry 4.0: A Real Industrial Case
}

\author{
Valeria Selicati*, Nicola Cardinale \\ Department of European and Mediterranean Cultures (DICEM), University of Basilicata, Via Lanera, 20 - 75100 Matera (MT), \\ Italy
}

Corresponding Author Email: valeria.selicati@unibas.it

https://doi.org/10.18280/ijht.390102

Received: 2 January 2021

Accepted: 10 February 2021

\section{Keywords:}

exergy analysis, hybrid modelling, Industry 4.0, Life cycle assessment, smart factory, sustainability

\begin{abstract}
The continuously rising cost of energy and its impact on environmental policy are the primary boost for industry to stay global competitive in terms of maximizing productivity and raising operational costs. The prevailing goal in the height of industry 4.0 is to inspect and optimize manufacturing processes. The challenge is to consider thermodynamics as simulation and modelling solution that enables improve energy production and help efforts to shift towards a smart factory. The aim of this paper is to demonstrate that using thermodynamic models as Exergy and Life Cycle thinking provides major benefits since it allows evaluation results more reliable and aims to develop a retrofitting approach that enhances the process to avoid system failures efficiently. Any practitioner may pick suitable sensing networks in line with Industry 4.0, in order to develop a monitoring and control infrastructure and improve any manufacturing system, getting it smarter. In this article, an explanatory case study on the production process of an Italian SME will be presented and discussed.
\end{abstract}

\section{INTRODUCTION}

Starting from the work carried out and published in the proceedings of the AIGE IIETA Congress on TI-IJES [1], the following paper is an extension and completion of the considerations and the analysis implemented in the paper.

With the constant increase in energy costs and their impacts on environmental policies, optimizing production and reducing operating costs is considered a critical tactic for companies to remain globally competitive. In the height of the fourth industrial revolution, the need to digitize and automate manufacturing processes emerges as another predominant goal. Currently, Industry 4.0 (I4.0 from now on) is highlighting the need to operate under environmental restrictions in order to be sustainability oriented. The environmental challenge that emerging innovations are facing is related to the increasing rise in electricity demand and the immediate need to implement low-carbon electricity systems [2]. The Key Enabling Technologies (KETs) of I4.0 [3], and the improvements that they foster, have an effect on raw materials flows, resources, goods, energy, pollution, properties and knowledge which, as a result, have a favorable or negative influence on environmental sustainability.

Sustainable manufacturing has been received awareness in terms of process control, energy analysis and low carbon emissions, especially within the I4.0 paradigm.

Wide knowledge about all the data related to materials, energy, machinery and auxiliary equipment is mandatory in order to optimize overall process performances.

Intelligent machine tools are built to be more integrated, effective and automatic. Investigations show that real-time process parameters optimization significantly reduces (of about $60 \%$ ) the energy consumption, while their current energy efficiency $(\eta)$ does not exceed the $30 \%$.

In the light of these innovating technologies, it is necessary to understand which methodologies are best suited to evaluate both qualitatively and quantitatively their sustainability and the one of the whole processes.

To this end, LCA is the most used tool that helps to quantify the consumption of resources flows throughout the entire life cycle of the process and its potential harm to the environment. The Exergetic Analysis (EA) adds information on the quality of the process in terms of efficiency.

The goal of this work is to show that hybridizing LCA with EA brings significant advantages: it makes the outcomes of the assessment more objective and it helps to develop retrofitting solution, thus enabling the process to automatically prevent any machine failures. In line with the Industry 4.0, any company would be able to select appropriate sensing infrastructure to enhance its monitoring and management system and redesign it, making it smarter.

The hybrid implementation of these two methods has proven to be a valuable tool for understanding process management alternatives and for optimizing and innovating production process technologies.

All these statements are endorsed by the assortment of hybrid methods existing in literature, which differ from each other for the distinct levels of hybridization between EA and LCA and for the variety of input and output flows that they consider.

The rest of this paper is organized as follows. The I4.0 paradigm and the role of sustainability related to it are described in Section 2. As KETs of I4.0 paradigm, the methodologies for dealing with manufacturing sustainability are widely reviewed in Section 3. A real industrial case is presented in Section 4, on which LCA, EA and hybrid EA- 
LCA are conducted and discussed, followed by the concluding remarks and further developments in Section 5.

\section{SUSTAINABILITY RELATED TO INDUSTRY 4.0}

Industry 4.0 was introduced in 2011 by German Government to indicate a set of technological changes in manufacturing systems by means of automations and ICT (Information and Communication Technologies), including Cyber-Physical Systems, Internet of Things, Simulation and Modelling, Big Data Analytics, Augmented Reality, Additive Manufacturing, Robotics, Cloud Computing and now also Blockchain. It aims to help incorporate and merge autonomous devices, human beings, physical objects and processes through operational stages in order to create different forms of digital data, functional and high agility value chains during the whole life cycle of a product, process or activity [4]. To this end, Liao et al. [5] made a comprehensive systematic literature review on I4.0 in all its facets including 224 papers out of 346 potential ones entered the data collection stage for qualitative and quantitative analysis.

The paradigm of Industry 4.0 is implemented in three dimensions [6, 7]:

Horizontal integration across the entire value creation network. It refers to the integration of the different IT systems used in the various stages of the manufacturing and business planning processes involving an exchange of products, resources and information;

End-to-end digital integration across the entire product life cycle. It allows smart business processes to be incorporated across the supply chain, including the factory floor and CPS services. The intelligent cross-linking and digitalization cover the application of an end-to-end solution using ITC which are embedded in a cloud;

Vertical integration and networked manufacturing systems. It refers to the integration of different IT systems at different hierarchical levels of the Factory itself during the manufacturing process, from product development to manufacturing, logistics and sales.

It is possible to list a set of key-features of I4.0 paradigm that lead to smartness [8-11]: a) automation, b) decentralization, c) real-time data acquisition, processing and communication, d) virtualization, e) modularity, f) flexibility, g) agility, h) efficiency, i) interoperability, j) prediction, and j) customization.

Today, I4.0 is supported in every field, not only manufacturing. Examples are in logistics, construction, transportation, medicine and surgery, food production, home automation and so on, even in our daily life with smartphones and watches.

While it is challenging for authors to decide on the right and unified concept of I4.0 and all associated supporting technologies, what the literature confirms is that the core of this paradigm is the vast network of sensors that are usable and open to everyone, as well as Cloud Computing.

It is evident that the guiding principles of I4.0 were not initially focused on providing alternatives to the ecological problems posed by manufacturing, but on improving efficiency and profitability.

If on one hand any company drops its basis of existence without economic profitability [12], very soon the companies have come to understand the value and the competitive advantages of proactive environmental practices. The related advantages span a broad spectrum [13], such as the reduction of pollution and environmental risks, and the enhancement in financial performance due to openings in new foreign markets. In fact, an eco-friendly organization would be able to obtain environmental certification with the associated boost in prestige. Industry 4.0 would be a step forward for more competitive manufacturing value development. In current literature, this phase is mainly defined as a commitment to the environmental aspect of sustainability. The distribution of services, i.e. goods, supplies, electricity and power, may be made more effective on the basis of insightful cross-linked value creating modules [14].

To date, the qualitative appraisal of the prospects for sustainable value development in Industry 4.0 has not been addressed holistically in a formal manner [15].

An interesting prospective exploration on both positive and negative cause-effects that all the features of I4.0 would bring in short and long term in the manufacturing field has been conducted by Bonilla et al. [16], considering the ideal point of sustainability as a threshold. In general, the trends of sustainability of environmental impacts due to the implementation of I4.0 are stage-dependent, since the trend results to be negative at the deployment stage, and positive during operation stage.

At long term and summing up ideas, smart manufacturing would bring some positive aspects on environmental sustainability, such as:

1) Building significant effects on sustainability through the whole supply chain;

2) Increasing the productivity with cost reductions;

3) Inventory reductions through real-time smart inventory management and traceability;

4) Real-time supply chain optimization \& supplier's integration that will enhance the development of a circular economy.

5) Decentralization of the collection of goods and services

6) Development of strategies and goods by taking into consideration customers' lifestyles;

7) Acquisition of new ecologic market awareness;

8) Achievement of shorter production time cycles;

9) Processing an amount of production calibrated to predicted needs, without further depletions.

10) $\mathrm{CO}_{2}$ emissions monitoring and control.

\section{METHODOLOGIES}

To understand how LCA and EA can be related to sustainability within I4.0 paradigm, let us briefly introduce the key enabling technologies, schematized in Figure 1, of Industry $4.0[3,7,17]$ :

Internet of Things (IoT). This technology enables companies to connect multiple devices, which are logistically remote, using sensors and microprocessors powered by software systems capable of transmitting information across the network. In this sense, it is necessary to clarify that such devices are internal to the production machines and that they can be built even after the completion of the latter thanks to the idea that, in the era of Industry 4.0, any physical entity has the potential of being smart with the intention of sharing information on its state and the state of the world in which it is situated. The Internet of Services (IoS) is associated with the strategic usage of the Web and innovative way of generating 
demand through the materialization of the Product-as-aService business model. Currently, producers of consumer goods are seeking to create a clear connection with customers and to improve their strategic advantage by delivering complementary services and developing new sources of income, and $\mathrm{IoS}$ is providing the requisite technical infrastructure.

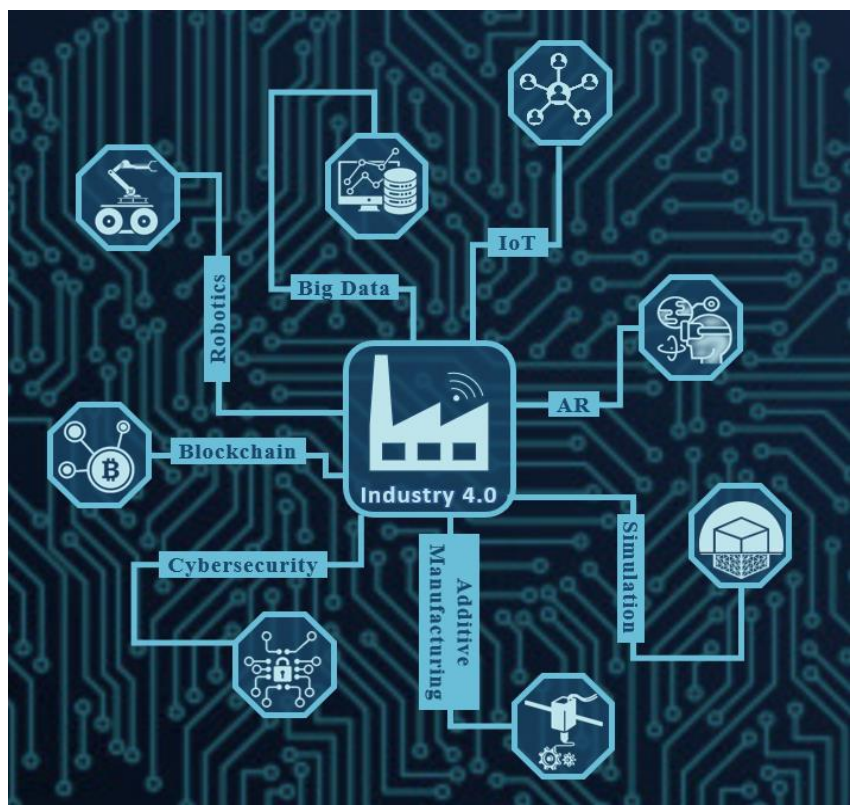

Figure 1. Industry 4.0 key enabling technologies

Big Data Analytics. refer to a new generation of technologies and architectures that enable organizations to economically extract value through discovering, capturing and analyzing very large volumes of a wide variety of data. Big data analytics enables contemporary organizations to better gain value from the massive amounts of information they already have and identify what is likely to happen next and what actions should be taken to achieve the optimal results. It leads to the Artificial Intelligence (AI).

Cybersecurity. I4.0 needs accessibility to the environment, with the goal of facilitating integration between various processes. While it is vital that mechanisms re put in communication to share information, it is equally important to monitor this sharing in view to protecting the data flows. In terms of knowledge sharing and data privacy, companies need cybersecurity protocols to better protect a device or a device collection.

Blockchain. Often identified as distributed ledger technology is the basis for cryptocurrencies such as Bitcoin and Ethereum, but the features go well beyond that. Blockchain is permanent, decentralized and redefines confidence because it allows open, safe, efficient and prompt public or private solutions.

Augmented reality (AR). Via 3D modelling, CAD and projection technologies, one of the most innovative applications in industry 4.0 is being promoted as Virtual Reality. Reference is made to a three-dimensional model capable of hosting a human operator within which the goal would be to evaluate the process in order to improve it in the design and commissioning phases, and also to facilitate the training of workers. For Augmented Reality, on the other side, reference is made to the idea of utilizing specific viewers to obtain extra details about the product simply by framing it.
This concept in Industry 4.0 transforms into the potential of getting access to automated and insightful product logistics, which helps to find them in the factory and to track order enforcement in real time. Such method helps to check the products from an aesthetic-functional point of view, while enabling the simulated placement of the same in the reference environment.

Robotics and Advanced Manufacturing Solutions. Robots, perceived as human operators ' partners, are and should be one of the key triggers. Such technologies are capable of rendering manufacturing processes more effective and increasing the productivity of the businesses that use them. Integrated and automated approaches assisted by human involvement in procedures that involve interactions between automatic and manual systems. Throughout this case, robots are actual interactive devices capable of sharing knowledge with other devices and human beings, continuing to remain autonomous while configuring the trajectories according to the needs of the output flow.

Additive manufacturing. It is a technology which, beginning with the digital drawing (aided by a CAD) of the product to be made, is capable of printing it by adding material. The nozzle can melt thin layers of powder and add one layer of material, either plastic or metal, on top of another, in order to create any shape. The great promise of this development is therefore the opportunity to switch from the digitally formalized concept straight to the product without even needing to go through intermediary stages, thereby freeing up room for alternative market models where it is possible to produce parts on demand.

Simulation and modelling techniques. Simulation refers to the concept of digital twin, meant as a mathematical model capable of representing a process, product or service in order to be able to carry out an analysis and to implement predictive performance techniques. This is the creation of a real process model, developed to collect valuable knowledge that can help companies minimize manufacturing costs, enhance the efficiency of the final product and reduce time-to-market. In smart factories, simulation and modelling would be required to exploit real-time data to replicate the physical environment in a simulated model that may involve computers, goods and humans.

Among the modelling techniques [18], and relevant to big data analytics, there are a) the model-based approach, that represents the real system involving the construction of a mathematical/physical model from the input parameters measured; b) the data-driven approach, focused on the analysis of a large number of raw historical data, came from a network of sensors and actuators, up until the creation of knowledge and behavioral models of the system itself. To this approach belong machine learning and data mining; c) the expert-system approach, method that emulates the decision-making ability of a human expert by solving a problem by reasoning about knowledge, and not by following the procedure of a developer as is the case in conventional programming. Since a single solution cannot be generalized to all various applications due to the complexities and heterogeneity that define manufacturing processes, alternative approaches have been formulated to solve the problems of particular use cases [19].

The growing refinement of manufacturing processes needs innovative methods to predict output failures and to identify sustainable operational profiles. Considering that, among KETs, there are big data analytics and modeling techniques, we focus now on the model-based approach, that is, the study 
of the process through physical (in our case, thermodynamic) models. The physical-thermodynamic models addressed in this work are Life Cycle Assessment and Exergy Analysis.

\subsection{Life Cycle Assessment framework}

The Life Cycle Assessment (LCA), regulated by ISO 14040 and ISO 14044, is a widespread analytical tool used to measure and analyze environmental flows through the entire life cycle of a product process or activity $[20,21]$ that goes to early bird design up until the waste scenario. The modern structure of the LCA proposed by ISO 14040 series consists of four main phases, and a last one, about the construction of an environmental indicator, as shown in Figure 2.

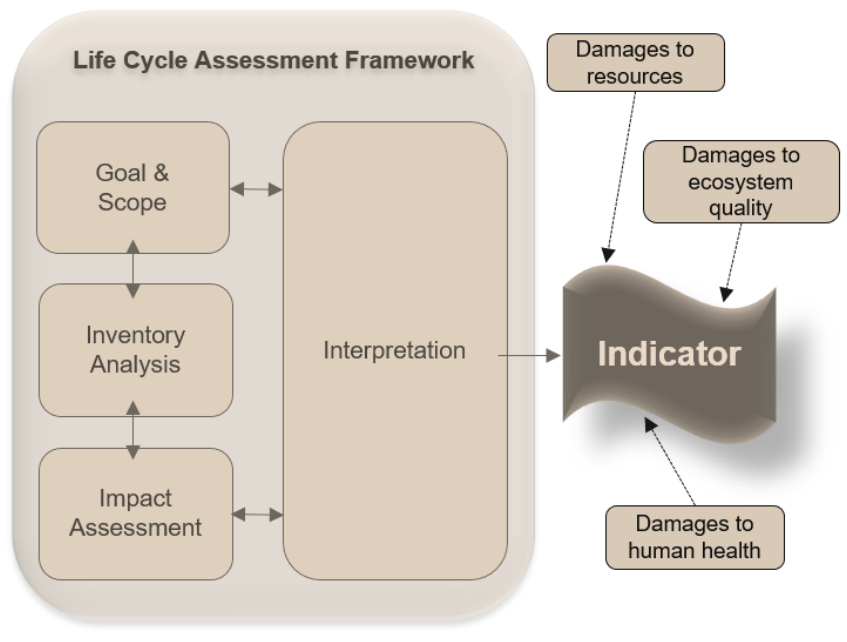

Figure 2. LCA framework according to ISO 14040

An in-depth overview of the LCA methodology and its regulation has been already developed by the authors in a previous work. In that case, the analysis was applied to the construction sector [22].

LCA is known to be an eco-design tool par excellence because it enables each aspect of a good or service to be analyzed in depth, exploring the nature of the whole life cycle. It facilitates the recognition of the most affecting systems and stages and also gives a good picture of the issues that need to be resolved by the action targets. It may be used to enhance the current product or to direct decision-making in the development of new goods [23]. Measurement of consumption and impacts, which allows to continuously work and improve products and processes, not just from a technical but also environmental point of view, is also an assertion of responsibility for all the stakeholders

This method is based on linear equations because it sums up quantities, see section 4.1 for an example.

LCA also has some limitations. The first is that it is more oriented towards the quantification of resources depleted during the process, but does not give information on efficiency and possible margins for improvement; the second is the reliance on various datasets relating to general or generic results, regardless of the specific process assessed. If data collection is poor, or if not enough data are available, the study will not lead to solid conclusions. The third is that LCA analyses are focused on assumptions and scenarios, since it simulates the local environment with a simplified model.

The most trivial part of an LCA is indeed the inventory phase (LCIA). The life cycle inventory analysis phase consists of determining both inputs (materials and energy resources) and outputs (emissions and environmental waste) to and from the product or process under study. Data on inputs and outputs are obtained and recorded for each phase within the system boundary, including raw material, energy, products, coproducts, waste, and emissions to air, soil, and water. All the data must be proportionate to the functional unit chosen in the beginning. Data collection may be especially time-intensive and resource-intensive, as it may cover both upstream processes (resource acquisition, processing and transport) as well as downstream processes (product consumption and disposal). To facilitate data collection as well as the full application of the LCA, the upstream and downstream data could be found in opensource or payment databases, such as Ecoinvent (payment, but the most complete) [24], ELCD (payment) [25], USLCI (opensource) [26] and so on. Software such as SimaPro or Gabi or OpenLCA helps users to conduct the evaluation in a more direct and intuitive way [27]. Obviously, they do require databases to operate and are thus not open to any practitioner.

\subsection{Exergy analysis}

Exergy Analysis is an analytical method to assess the sustainable efficiency of manufacturing processes [28]. According to the second law of thermodynamics, EA is a nonlinear method due to process irreversibilities, see section 4.2 for a proof.

Exergy is defined as "maximum theoretical useful work obtainable as the system is brought into complete thermodynamic equilibrium with the thermodynamic environment while the system interacts with this environment only" [29]. When a system is in perfect equilibrium with its reference environment (i.e. no temperature gradients are present), there is no exergy at all. More the exergy is created, more the system is far from its equilibrium.

Exergy has four main components, excluding radioactive, gravitational, electrical, and surface tension effects: potential, chemical, physical, and kinetic. Kinetic exergy is especially important when speeds are large, as in the case of turbines, whereas potential exergy is particularly relevant for electrical or hydraulic systems. For many functional applications concerning manufacturing processes, potential exergy and kinetic exergy are negligible [30].

EA provides a perfect frame to evaluate efficiency in a single metric, which is a sort of measure of reversibility of the processes, reducing the interpretation issues inherent the LCA.

Exergy is conserved only in reversible processes (ideal processes, as it is Carnot cycle). In real processes, which are irreversible, a quantity of exergy is always destructed.

To this aim, the two ratios below represent a good interpretation of process performance.

- General exergy efficiency:

$$
\eta_{g}=\frac{\sum \dot{E} x^{\text {product }}}{\sum \dot{E} x^{\text {input }}}
$$

- Net use efficiency:

$$
\eta_{n}=\frac{\sum \dot{E} x^{\text {output }}}{\sum E x^{\text {input }}}
$$


In real processes, these ratios are always $<1$. The distinction between Ex product and Ex ${ }^{\text {output }}$ is in the output flows taken into account in the sum: 'product' implies just the flows involved in the processing of the required performance; 'output' is the total amount of outlet flows (productions and losses) involved in the process or activity under analysis.

\subsection{Hybrid/Coupled EA-LCA}

While classical LCA tools have a major emphasis on emissions, EA is much more efficiency oriented [31]. Although the time period evaluated during the LCA is larger than that seen during an EA, all approaches are time dependent. Both during LCA and EA, it is important to establish a context of the analysis in which system boundary is named in LCA and the definition of the reference environment corresponds in EA [32]. Both LCA and EA consist of mass and energy balances, but LCA may not provide a standard metric, in fact several authors consider the Life Cycle a multidimensional evaluation approach [31], while EA has a single metric and this contributes to greater comparability and understanding.

Based on the literature, there are positive opinions on the utility of Exergy coupled with LCA as a metric of sustainability, as they are complementary tools [33, 34].

So why not jointly use both methods? Every approach expresses the same problem: the use of two separate points of view theoretically contributes to the application of the strengths of the combined strategies, while reducing the specific shortcomings [35]. The integration of EA and LCA is thought to be possible to model a monitoring strategy which is a fundamental precondition for the implementation of Industry 4.0 technologies.

Hybridization may be achieved in many forms. For example, the two analyzes may be conducted independently and the outcomes of one and the other can ultimately be merged to give a more comprehensive image of the process or product being evaluated. Another way could be splitting EA into unitprocesses, each of which assesses a phase of the life cycle. There is not yet a pure hybrid model under which there is just an equation or algorithm based on the principles of the LCA, and those of the EA.

These assertions are backed by the number of hybrid approaches in the literature, which vary from one another in terms of the distinct degrees of hybridization between EA and LCA and the diversity of input and output flows that are inventoried, see [36] for a deepen review about these methods and their issues. Far from describing each method as it is not the core of this work, here is a chronological list of hybrid/coupled methods used in manufacturing:

- $\quad$ Cumulative Exergy Consumption (CExC) [37], 1987;

- $\quad$ Exergetic Life Cycle Assessment (ELCA) [38], 1997;

- $\quad$ Extended Exergy Accounting (EEA) [39], 2001;

- $\quad$ Life Cycle Exergy Analysis (LCEA) [40], 2001;

- Thermodynamically based-LCA [41], 2002;

- Cumulative Exergy Demand (CExD) [42], 2006;

- Thermo Ecological Cost (TEC) [43], 2007;

- Cumulative Extraction from Natural Environment (CEENE) [44], 2007;

- Exergoenvironmental Analysis [45], 2008;

- Total Cumulative Exergy Loss (TCExL) [46], 2012;

- Exergy based Input-Output analysis (ExIO) [47], 2014.

\section{CASE STUDY}

We now focus the attention on a real industrial case of an Italian SME that produces all the small accessories for aluminum window and door frames.

The process under analysis is the window handle, as shown in Figure 3, composed by an aluminum knob, a case, covercase and a spindle in zamak, a bushing and a spacer in Delrin and other auxiliary components as metallic screws and springs.

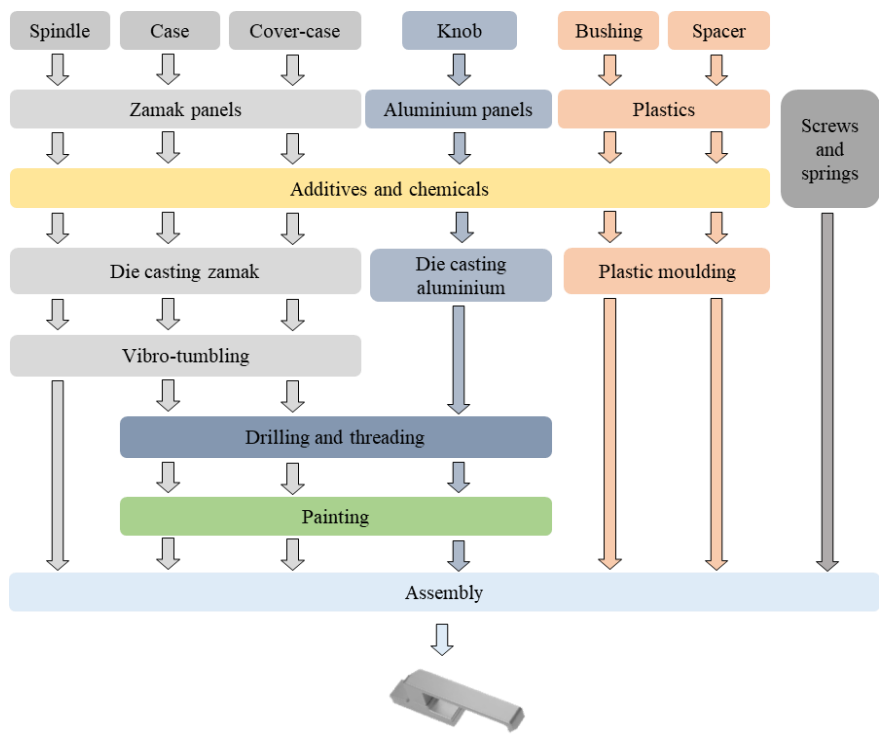

Figure 3. Manufacturing sub-processes related to the functional unit, the handle

The goal and scope of this case study is to carry out a sustainability evaluation by LCA, EA and hybrid EA-LCA.

The following analysis is carried out with the same starting assumptions, saying, same functional unit, same system boundaries and same reference flows.

The functional unit, consistent with the goal and scope, is one piece of finished product which, in our case, corresponds to a single window handle. The functional unit provides a structure for the standardization (in a computational sense) of input and output data on the basis of which the performance of the analyzed process may be defined.

The system boundaries have been chosen according to the goal and scope. An appropriate unit of measurement for the reference flow should be calculated for all the process units that relate to the output of the functional unit under analysis (e.g. the quantity of energy used in manufacturing, the $\mathrm{kg}$ of raw materials used, etc.). Both processes from the exploitation of raw materials to the processing and use of materials have been included in the model. In the case of shipping, the analysis focused on those required for the supply of semifinished and primary products. Waste treatments have been included, except for recycling, for which only transport to the recovery plant has been included.

Transport relevant to the shipment of the final product is omitted from the analysis, since the marketplace is characterized by consumers from all over the world for whom it is impossible to create forecasts or assumptions of location and plant maintenance operations.

For the specification of reference flows, the process is shown as a basic series of operations (shown in Figure 3) consisting of the description of its primary unit-function (i.e. subprocesses), its cycle times, and the efficient classification 
of its primary and secondary elements to be included in the analysis, as well as upstream and downstream processes.

\subsection{Life cycle assessment}

LCA's environmental analysis provides details on resource use, electricity use, carbon emissions over the product life cycle and future environmental effects in terms of $\mathrm{kgCO}_{2 \text { eq. }}$. Impact category for the Global Warming Potential predictor

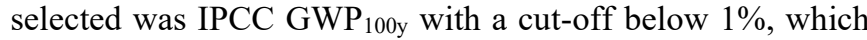
indicates that all subprocesses or components that contribute less than $1 \%$ to overall consumption are neglected in the final results.

The program selected to do this LCA analysis is SimaPro v.9. This is a comprehensive IT tool which requires a number of databases, including the categories needed to describe the life cycle; in fact, they are classified and listed in each database: products, procedures, energy and transport systems, recycle methods and waste management. The database used is Ecoinvent v.3.

In Table 1 the results are shown in matrix form, in order to link each environmental impacts of the components of the handle to those related to each sub-process.

The following Figure 4 illustrates the overall impacts of one handle. The evaluation of the impacts for the GWP reported a total value of $3.2580 \mathrm{kgCO}_{2 \text { eq }}$ per piece on one year. As seen clearly in Figure 4, Figure 5 and Table 1, the most affected component is the knob, of which die cast aluminum subprocess is connected as the most impacting, representing the $61 \%$ of the total. The knob involves the $62 \%$ of the overall impact. It follows the case and the cover case in zamak with the $18.50 \%$ and $11.10 \%$, of which die casting zamak is the most impacting sub-process with $34.30 \%$ of the total.

This implies that the goal for optimization is to focus on aluminum die-as a priority sub-process.

Table 1. LCA impact assessment by IPCC-GWP ${ }_{100 \mathrm{y}}$ all expressed in $\mathrm{kgCO}_{2 \mathrm{eq}}$

\begin{tabular}{|c|c|c|c|c|c|c|c|c|}
\hline & Die casting Zamak & $\begin{array}{l}\text { Die casting } \\
\text { Aluminum }\end{array}$ & $\begin{array}{c}\text { Plastic } \\
\text { molding }\end{array}$ & $\begin{array}{c}\text { Vibro- } \\
\text { tumbling }\end{array}$ & $\begin{array}{c}\text { Drilling and } \\
\text { threading }\end{array}$ & Painting & Assembly & Total \\
\hline Bushing & & \multirow{6}{*}{1.9842} & 0.0150 & & & & & 0.0150 \\
\hline Case & 0.6030 & & & 0.0030 & & 0.0043 & & 0.6103 \\
\hline Cover-case & 0.3620 & & & 0.0010 & & 0.0056 & & 0.3686 \\
\hline Knob & \multirow{3}{*}{0.1524} & & & \multirow{3}{*}{0.0006} & 0.0074 & 0.0134 & & 2.0050 \\
\hline Spindle & & & & & & & & 0.1530 \\
\hline Assembly & & & & & & & 0.1060 & 0.1060 \\
\hline Total & 1.1175 & 1.9842 & 0.0150 & 0.0045 & 0.0074 & 0.0233 & 0.1060 & 3.2580 \\
\hline
\end{tabular}
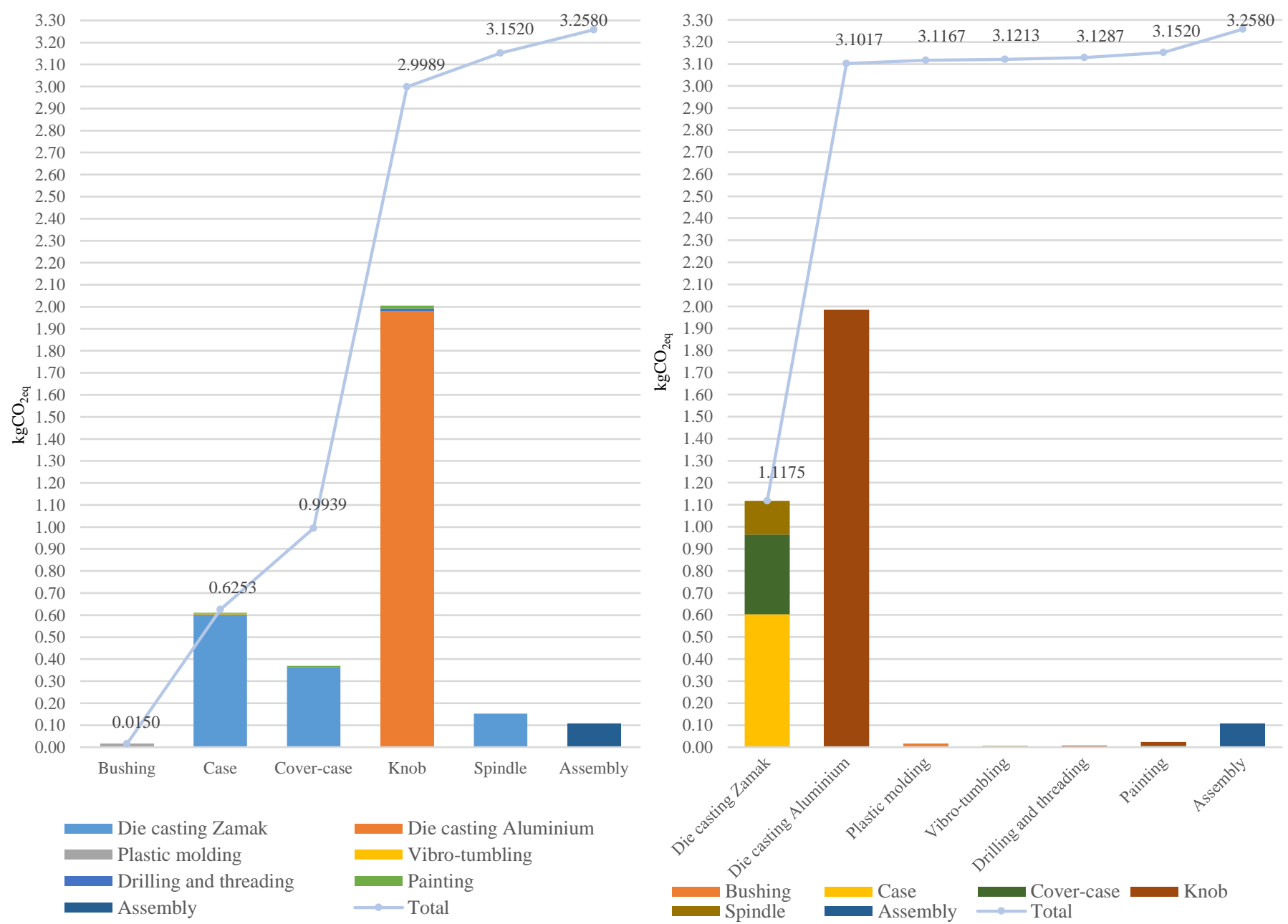

Figure 4. IPCC-GWP $100 \mathrm{y}$ : cumulative impact of each handle component related to the sub-process and vice-versa, in $\mathrm{kgCO}_{2 \mathrm{eq}}$ 

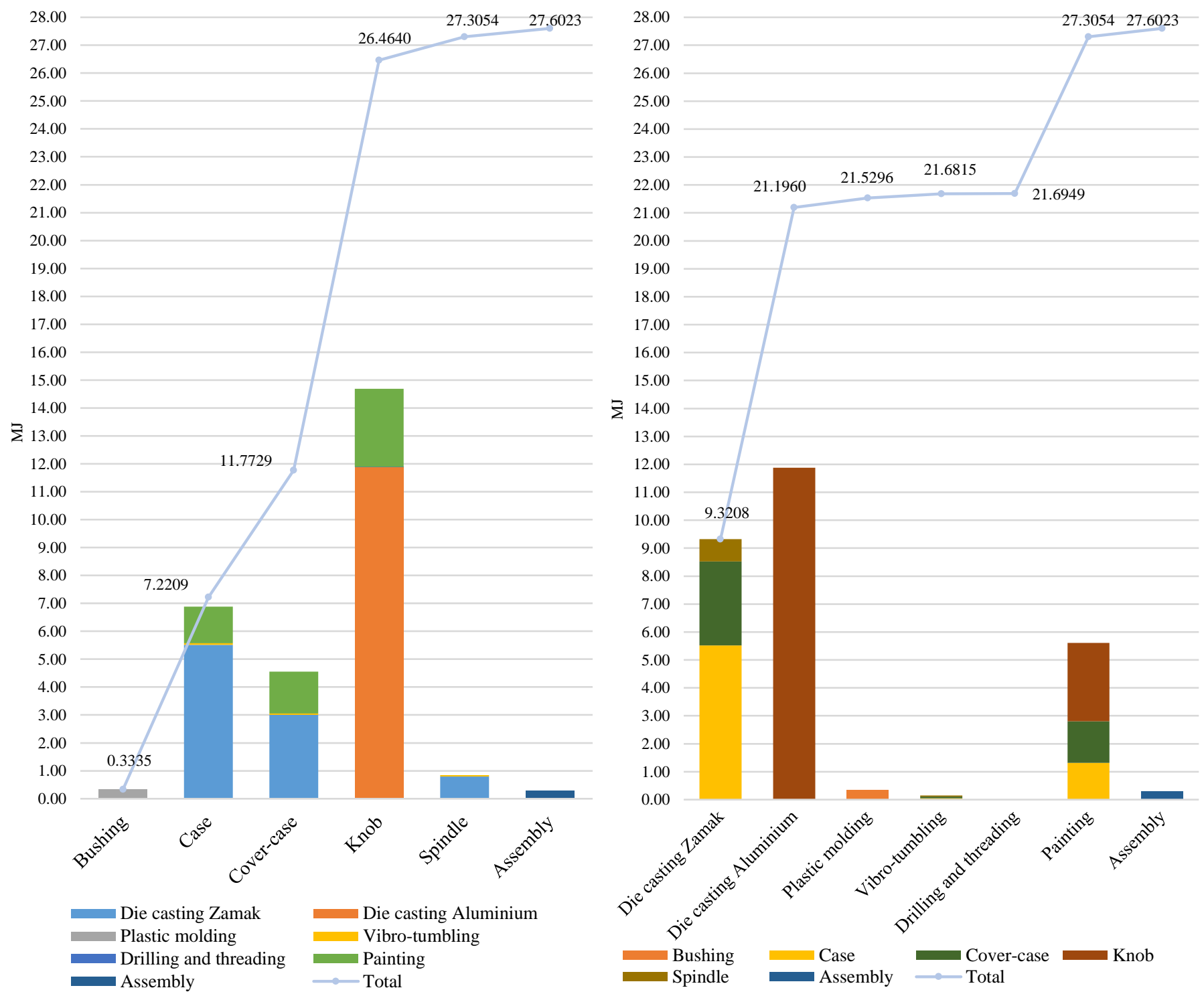

Figure 5. CExD: Cumulative impact of each handle component related to the sub-process and vice-versa, in $\mathrm{MJ}$

\subsection{Exergy analysis}

Considering a generic sub-process in the overall manufacturing process of the handle, an example of inventoried input and output flows are shown in Figure 6.

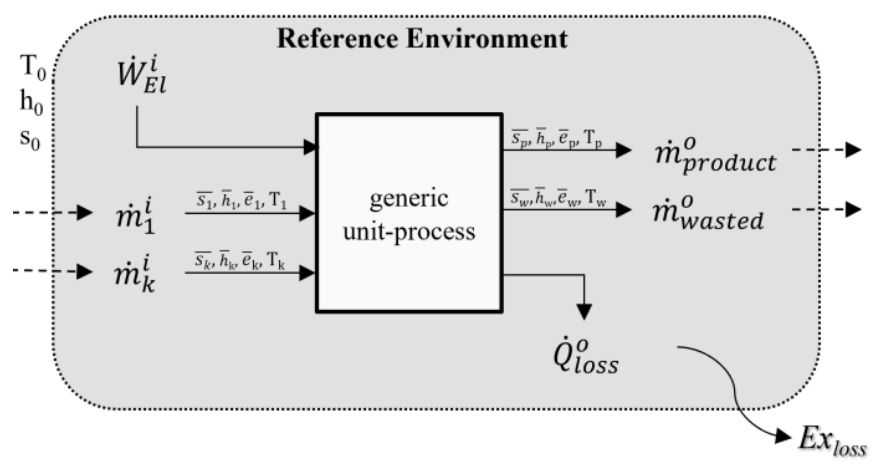

Figure 6. In/out flows of a generic thermodynamic system

Reference flows are uniquely identified in its balance equations [48]. In our industrial case reference flows are:

Mass flow balance:

$$
\sum_{k} \dot{m}_{k}^{i}=\sum_{k} \dot{m}_{k}^{o}
$$

Energy flow balance:

$$
\sum_{c} \dot{H}_{c}^{i}+\sum_{d} \dot{W}_{d}^{i}+\sum_{p} \dot{Q}_{p}^{i}=\sum_{c} \dot{H}_{c}^{o}+\sum_{d} \dot{W}_{d}^{o}+\sum_{p} \dot{Q}_{p}^{o}
$$

Exergy flow balance:

$$
\begin{aligned}
\sum_{c} E x_{c}^{i}+\sum_{d} \dot{W}_{d}^{i} & +\sum_{p}\left(1-\frac{T_{0}}{T_{e}}\right) \dot{Q}_{p}^{i} \\
& =\sum_{c} \dot{E} x_{c}^{o}+\sum_{d} \dot{W}_{d}^{o} \\
& ++\sum_{p}\left(1-\frac{T_{0}}{T_{e}}\right) \dot{Q}_{p}^{o}+\text { Ex }_{\text {loss }}
\end{aligned}
$$

where,

Specific enthalpy and enthalpy

$$
\begin{gathered}
\bar{h}=c \cdot\left(T-T_{0}\right) \\
H=\dot{m} \cdot \bar{h}
\end{gathered}
$$


Specific entropy

$$
\bar{S}=c \cdot \ln \left(\frac{T}{T_{0}}\right)
$$

Specific exergy and exergy

$$
\begin{gathered}
\bar{e}=\left[\bar{h}-\bar{h}_{0}-T_{0} \cdot\left(\bar{s}-\bar{s}_{0}\right)\right] \\
E x=\dot{m} \cdot \bar{e}
\end{gathered}
$$

The optimization criteria in the exergetic analysis is, in essence, the minimization of the term Ex loss $_{\text {(exergetic loss is }}$ proportional to the entropy generated) and this latter is the cause of less-than-theoretical efficiency of the process.

As can be seen from Eqns. (5), (6), (8) and (9), temperature variations play a key role in the exergetic equilibrium. The greater the disparity in temperatures in two transition phases, the greater the energy produced.

When an inventory of the data required to carry out the EA was made, it was observed that the temperatures of the mass flows in and out of the plant were not tracked at any operational phase of the processes. The only temperatures controlled were the environment temperature and the temperature of the furnaces. Insufficient knowledge to do the appropriate analysis. This drawback shows how, well before the analysis itself was carried out, the EA inventory was useful for the detection of the first requirement for the measuring system as the real-time monitoring of the temperatures of the input and output material flows of the system and of each process unit (sub-systems). The sampling frequency becomes an additional important requirement.

The further definition of the complete set of measuring and monitoring devices has not been addressed in this work but will be object of future investigations.

\subsection{Hybrid EA-LCA}

A very useful method that allows any practitioner to overcome the problem of the real-time monitoring of temperatures is the Cumulative Exergy Demand (CExD) implemented on SimaPro v.9 software. SimaPro's CExD bases on the methodology introduced by Bösch et al. in 2006 [42] to quantify the life cycle exergy demand of a product or process.

The analysis bases on the Eq. (11) below [49], where kinetic, potential and nuclear exergy are already ignored, leaving only the chemical and the thermal in the calculation.

$$
C E x D=\sum_{k} \dot{m}_{k} \cdot E x_{c h, k}+\sum_{y} n_{y} \cdot r_{E x-E x_{t h}, y}
$$

The creation of broad life-cycle databases, such as Ecoinvent, provide a resource requirement for each unit process. With the aid of the software SimaPro, therefore, better CExD scores may be calculated that specifically reflect the exergy demand of a specific functional unit.

As regards the CExD carried out in the case study, the only metric is the amount of Exergy loss expressed in MJ. The evaluation is carried out through the life-cycle stages and all the starting assumptions are equivalent to those made for the LCA analysis.

The results are shown in Table 2 .

The following Figure 5 illustrates the overall impacts of one handle. The evaluation of the impacts for the CExD reported a total value of $27.60 \mathrm{MJ}$ per piece.

The findings of the implementation of the CExD returned conclusions totally equivalent to those obtained with the LCA. Die casting aluminum results to be the most critical subprocess, representing the $43 \%$ of the total impact. The knob proven to be the most critical component of the handle, representing the $53.22 \%$ of the overall impacts. It follows the case and cover case in zamak, representing the $25 \%$ and $16.50 \%$ of the overall impacts, to which corresponds the die casting zamak with $33.80 \%$ of the total. This partially applies to the adoption of the same software and the same starting assumptions as the reference flows, system boundaries, etc. As Figure 6 indicates, according to $\mathrm{CExD}$, this time the painting sub-process has a larger effect than the IPCC-GWP100y. This could be attributed to the specific weighting system of the method, contributing to the overall impact assessment, i.e., in $\mathrm{CExD}$, the paint consumption is more impacting than assembly process, overturning the situation provided in LCA analysis.

\subsection{Discussion on results}

IoT technology has created exciting opportunities to develop powerful tools for monitoring and management production through sensor systems [50]. However, there are still difficulties in the application of this technology, such as, for example, what kind of data needs to be collected and how to properly acquire it, because there are multiple consumption points and lots of sub-processes in the system, and how to specifically analyze the data collected from multi-sensors in order to determine the real operational state of the overall system and all the sub-systems as well, as the data acquired by a single sensor (e.g. a power sensor, a temperature sensor) may not provide sufficient information [51]. For a hierarchical structure such as those developed by Lee et al. [52], process

\begin{tabular}{|c|c|c|c|c|c|c|c|c|}
\hline & Die casting Zamak & $\begin{array}{l}\text { Die casting } \\
\text { Aluminum }\end{array}$ & $\begin{array}{c}\text { Plastic } \\
\text { molding }\end{array}$ & $\begin{array}{c}\text { Vibro- } \\
\text { tumbling }\end{array}$ & $\begin{array}{c}\text { Drilling and } \\
\text { threading }\end{array}$ & Painting & Assembly & Total \\
\hline Bushing & & \multirow{6}{*}{11.8752} & 0.3335 & & & & & 0.3335 \\
\hline Case & 5.5187 & & & 0.0532 & & 1.3155 & & 6.8874 \\
\hline Cover-case & 3.0028 & & & 0.0566 & & 1.4925 & & 4.5519 \\
\hline Knob & \multirow{3}{*}{0.7993} & & & & 0.0134 & 2.8025 & & 14.6911 \\
\hline Spindle & & & & 0.0421 & & & & 0.8414 \\
\hline Assembly & & & & & & & 0.2969 & 0.2969 \\
\hline Total & 9.3208 & 11.8752 & 0.3335 & 0.1519 & 0.0134 & 5.6105 & 0.2969 & 27.6023 \\
\hline
\end{tabular}
inefficiencies and effect-relationships can be detected and optimized automatically.

Table 2. LCA impact assessment by CExD all expressed in MJ 


\section{CONCLUSIONS}

The literature review has demonstrated that sustainability is not explicitly one of the core keywords for Industry 4.0. To order for sustainability to really fit under the i4.0 framework, it is necessary to add it to the KETs of the paradigm and to incorporate the Circular Economy as one of its key-features, not only as contingent benefit. In fact, resuming the review carried out by Bonilla et al. on the effects that the implementation of Industry 4.0 paradigm would have on the environment, the findings suggest that the features and the KETs provide a variety of possibilities for environmental sustainability when properly designed. On the other side, the long-term scenario of Industry 4.0 is directly related to social responses as well as public policy, regulatory systems and homogeneous distribution. Heterogeneity between nations embracing Industry 4.0 as well as between companies with different levels of digitalized technology may build market segments of disparity and non-sustainability trends.

The models based on thermodynamic analyses, hence based on discrete variables, represent an innovative and interesting strategy for maximizing the sustainability of the manufacturing system performances facilitating the management of new smart manufacturing processes, thus driving the practitioners employing a suitable sensing system and information structure for a real-time monitoring, hence couple model-based approaches with data-driven ones and gather a comprehensive knowledge up until the implementation of a predictive manufacturing system. Datadriven approaches allow to analyze parameters within different fields, e.g. product, process and logistics, and enable the extrapolation of forms of cause-effect interactions that traditional methodologies (i.e. statistical models, physical models) cannot identify on their own. In this way, quality issues may also be defined and managed along with sustainability concerns.

Sensing systems for real-time state monitoring of dynamic manufacturing processes can be a framework for developing and testing new business models in the context of I4.0, as this automatically led to improved energy and technological performance, resulting in a reduction of consumption and maintenance and thus to several economic advantages.

\section{REFERENCES}

[1] Selicati, V., Cardinale, N. (2020). Benchmarking sustainability on an industrial case within Industry 4.0 paradigm: Advantages of involving exergetic analysis in life cycle thinking. Tecnica Italiana - Italian Journal of Engineering Science, 63(2): 244-250. https://doi.org/10.18280/ti-ijes.642-418

[2] Wang, S., Wan, J., Li, D., Zhang, C. (2016). Implementing smart factory of industrie 4.0: an outlook. International Journal of Distributed Sensor Networks, 12(1): 3159805. https://doi.org/10.1155/2016/3159805

[3] Chiarello, F., Trivelli, L., Bonaccorsi, A., Fantoni, G. (2018). Extracting and mapping industry 4.0 technologies using Wikipedia. Computers in Industry, 100: https://doi.org/10.1016/j.compind.2018.04.006

[4] Tay, S.I., Malaysia, T.H.O., Raja, P., Pahat, B., Hamid, N.A.A., Ahmad, A.N.A. (2018). An overview of Industry 4.0: Definition, components, and government initiatives.
Control Systems, 10: 10.

[5] Liao, Y., Deschamps, F., Loures, E. de F.R., Ramos, L.F.P. (2017). Past, present and future of Industry 4.0 - a systematic literature review and research agenda proposal. International Journal of Production Research, 55(12): 3609-3629. https://doi.org/10.1080/00207543.2017.1308576

[6] Vaidya, S., Ambad, P., Bhosle, S. (2018). Industry 4.0 A Glimpse. Procedia Manufacturing, 20: 233-238. https://doi.org/10.1016/j.promfg.2018.02.034

[7] Posada, J., Toro, C., Barandiaran, I., Oyarzun, D., Stricker, D., de Amicis, R., Pinto, E.B., Eisert, P., Dollner, J., Vallarino, I. (2015). Visual Computing as a Key Enabling Technology for Industrie 4.0 and Industrial Internet. IEEE Computer Graphics and Applications, 35(2): 26-40. https://doi.org/10.1109/MCG.2015.45

[8] Lasi, H., Fettke, P., Kemper, H.G., Feld, T., Hoffmann, M. (2014). Industrie 4.0. Wirtschaftsinformatik, 56(4): 261-264. https://doi.org/10.1007/s11576-014-0424-4

[9] Kagermann, H., Wahlster, W., Helbig, J. Recommendations for Implementing the Strategic Initiative Industrie 4.0; National Academy of Science and Engineering: Munich, Germany, 2013. http://digital.bib-

bvb.de/webclient/DeliveryManager?custom_att_2=simp le_viewer\&pid=5744125, accessed on Jan.16, 2020.

[10] Hermann, M., Pentek, T., Otto, B. (2015). Design Principles for Industrie 4.0 Scenarios: A Literature Review. https://doi.org/10.13140/RG.2.2.29269.22248

[11] Ghobakhloo, M. (2018). The future of manufacturing industry: A strategic roadmap toward Industry 4.0. Journal of Manufacturing Technology Management, 29(6): 910-936. https://doi.org/10.1108/JMTM-02-20180057

[12] Markley, M.J., Davis, L. (2007). Exploring future competitive advantage through sustainable supply chains. International Journal of Physical Distribution \& Logistics Management, 37(9): 763-774. https://doi.org/10.1108/09600030710840859

[13] Kiel, D., Müller, J.M., Arnold, C., Voigt, K.I. (2017). Sustainable industrial value creation: benefits and challenges of industry 4.0. International Journal of Innovation Management, 21(08): 1740015. https://doi.org/10.1142/S1363919617400151

[14] Stock, T., Seliger, G. (2016). Opportunities of Sustainable Manufacturing in Industry 4.0. Procedia CIRP, 40: 536-541. https://doi.org/10.1016/j.procir.2016.01.129

[15] Stock, Tim, Obenaus, M., Kunz, S., Kohl, H. (2018). Industry 4.0 as enabler for a sustainable development: A qualitative assessment of its ecological and social potential. Process Safety and Environmental Protection, 118: 254-267. https://doi.org/10.1016/j.psep.2018.06.026

[16] Bonilla, S., Silva, H., Terra da Silva, M., Franco Gonçalves, R., Sacomano, J. (2018). Industry 4.0 and sustainability implications: A scenario-based analysis of the impacts and challenges. Sustainability, 10(10): 3740. https://doi.org/10.3390/su10103740

[17] Ruppert, T., Jaskó, S., Holczinger, T., Abonyi, J. (2018). Enabling technologies for operator 4.0: A survey. Applied $\quad$ Sciences, $\quad 8(9)$ : 1650. https://doi.org/10.3390/app8091650

[18] Skliros, C., Esperon Miguez, M., Fakhre, A., Jennions, I. 
(2018). A review of model based and data driven methods targeting hardware systems diagnostics. Diagnostyka, 20(1): 3-21. https://doi.org/10.29354/diag/99603

[19] Tidriri, K., Chatti, N., Verron, S., Tiplica, T. (2016) Bridging data-driven and model-based approaches for process fault diagnosis and health monitoring: A review of researches and future challenges. Annual Reviews in Control, 42:

63-81 https://doi.org/10.1016/j.arcontrol.2016.09.008

[20] UNI EN ISO 14040:2006. (2006). http://store.uni.com/catalogo/index.php/uni-en-iso14040-2006.html, accessed on Feb. 05, 2019.

[21] ISO 14044:2006. ISO. (2006) http://www.iso.org/cms/render/live/en/sites/isoorg/conte nts/data/standard/03/84/38498.html, accessed on Oct. 21, 2019.

[22] Selicati, V., Cardinale, N., Dassisti, M. (2020). Evaluation of the sustainability of energy retrofit interventions on the historical heritage: A case study in the city of Matera, Italy. International Journal of Heat and Technology, 38(1): 17-27. https://doi.org/10.18280/ijht.380103

[23] Navajas, A., Uriarte, L., Gandía. L. (2017). Application of eco-design and life cycle assessment standards for environmental impact reduction of an industrial product. Sustainability, $\quad 9(10)$ :

1724. https://doi.org/10.3390/su9101724

[24] Weidema, B., Hischier, R., Althaus, H.J., Bauer, C., Doka, G., Dones, R., Frischknecht, R., Jungbluth, N., Nemecek, T., Primas, A., Wernet, G. (2009). Code of Practice. Final report ecoinvent data v2.1 No. 2. Swiss Centre for Life Cycle Inventories, Dübendorf, CH., 40., https://www.ecoinvent.org/files/200905_weidema_hisc hier_codeofpractice_v2.1.pdf, accessed on Nov. 28 , 2019.

[25] Mathieux, F., Recchioni, M., Schau, E.M., Goralczyk, M., European Commission, Joint Research Centre, \& Institute for Environment and Sustainability. (2013). ILCD data network and ELCD database current use and further needs for supporting environmental footprint and life cycle indicator projects. Publications Office. https://eplca.jrc.ec.europa.eu/uploads/ILCD-DN-andELCD-current-use-and-further-needs-for-supportingEF-and-LCIndicator-Projects.pdf, accessed on Oct. 21, 2019.

[26] U.S. Life Cycle Inventory Database | NREL. (n.d.). Retrieved $21 \quad$ October 2019, from https://www.nrel.gov/lci/, accessed Oct. 21, 2019.

[27] Dincer, I., Bicer, Y. (2018). 1.27 life cycle assessment of energy. In Comprehensive Energy Systems, pp. 10421084. Elsevier. https://doi.org/10.1016/B978-0-12809597-3.00134-6

[28] Gong, M., Wall, G. (2001). On exergy and sustainable development-Part 2: Indicators and methods. Exergy, An International Journal, 1(4): 217-233. https://doi.org/10.1016/S1164-0235(01)00030-9

[29] Bakshi, B.R., Gutowski, T., Sekulic, D. (2011). Thermodynamics and the Destruction of Resources. Cambridge University
www.cambrige.org/9780521884556

[30] Dincer, I., Rosen, M.A. (2013). Exergy. Elsevier. https://doi.org/10.1016/B978-0-08-097089-9.01001-9

[31] Moya, C., Domínguez, R., Van Langenhove, H., Herrero,
S., Gil, P., Ledón, C., Dewulf, J. (2013). Exergetic analysis in cane sugar production in combination with Life Cycle Assessment. Journal of Cleaner Production, 59: 43-50. https://doi.org/10.1016/j.jclepro.2013.06.028

[32] Romero, J.C., Linares, P. (2014). Exergy as a global energy sustainability indicator. A review of the state of the art. Renewable and Sustainable Energy Reviews, 33: 427-442. https://doi.org/10.1016/j.rser.2014.02.012

[33] Pati, D.S.N., Pahuja, A., Selvarajan, M. (2009). Integration of exergy with lca for sustainability. 11th NCB International Seminar, National Council for Cement and Building Material, Ballabgarh, 11.

[34] Portha, J.F., Louret, S., Pons, M.N., Jaubert, J.N. (2010). Estimation of the environmental impact of a petrochemical process using coupled LCA and exergy analysis. Resources, Conservation and Recycling, 54(5): 291-298.

https://doi.org/10.1016/j.resconrec.2009.09.009

[35] Milanovic, B., Agarski, B., Vukelic, D., Budak, I., Kiss, F. (2017). Comparative exergy-based life cycle assessment of conventional and hybrid base transmitter stations. Journal of Cleaner Production, 167: 610-618. https://doi.org/10.1016/j.jclepro.2017.08.176

[36] Selicati, V., Cardinale, N., Dassisti, M. (2021). The interoperability of exergy and Life Cycle Thinking in assessing manufacturing sustainability: A review of hybrid approaches. Journal of Cleaner Production, 286: 124932. https://doi.org/10.1016/j.jclepro.2020.124932

[37] Szargut, Jan, Morris, D.R. (1987). Cumulative exergy consumption and cumulative degree of perfection of chemical processes. International Journal of Energy Research, 11(2): 245-261. https://doi.org/10.1002/er.4440110207

[38] Cornelissen, R.L. (1997). Thermodynamics and sustainable development: The use of exergy analysis and the reduction of irreversibility.

[39] Sciubba, E. (2001). Beyond thermoeconomics? The concept of Extended Exergy Accounting and its application to the analysis and design of thermal systems. Exergy, An International Journal, 1(2): 68-84. https://doi.org/10.1016/S1164-0235(01)00012-7

[40] Wall, G., Gong, M. (2001). On exergy and sustainable development-Part 1: Conditions and concepts. Exergy, An International Journal, 1(3): 128-145. https://doi.org/10.1016/S1164-0235(01)00020-6

[41] Dewulf, J., Bösch, M.E., Meester, B.D., Vorst, G.V., der, Langenhove, H.V., Hellweg, S., Huijbregts, M.A.J. (2007). Cumulative Exergy Extraction from the Natural Environment (CEENE): A comprehensive Life Cycle Impact Assessment method for resource accounting. Environmental Science \& Technology, 41(24): 84778483. https://doi.org/10.1021/es0711415

[42] Bösch, M.E., Hellweg, S., Huijbregts, M.A.J., Frischknecht, R. (2007). Applying cumulative exergy demand (CExD) indicators to the ecoinvent database. The International Journal of Life Cycle Assessment, 12(3): 181-190. https://doi.org/10.1065/lca2006.11.282

[43] Szargut, J., Stanek, W. (2007). Thermo-ecological optimization of a solar collector. Energy, 32(4): 584-590. https://doi.org/10.1016/j.energy.2006.06.010

[44] Dewulf, J., Van Langenhove, H. (2002). Assessment of the sustainability of technology by means of a thermodynamically based life cycle analysis. Environmental Science and Pollution Research, 9(4): 
267-273. https://doi.org/10.1007/BF02987502

[45] Meyer, L., Tsatsaronis, G., Buchgeister, J., Schebek, L. (2008). Exergoenvironmental analysis for evaluation of the environmental impact of energy conversion systems. Energy, 34(1): 75-89. https://doi.org/10.1016/j.energy.2008.07.018

[46] Stougie, L., Kooi, H.J., van der, Stikkelman, R.M. (2012). Electricity production from renewable and nonrenewable energy sources: A comparison of environmental, economic and social sustainability indicators with exergy losses throughout the supply chain. ECOS 2012: Proceedings of the 25th International Conference on Efficiency, Cost, Optimization, Simulation, and Environmental Impact of Energy Systems, pp. 247-1-247-15.

[47] Rocco, M.V. (2014). Primary exergy cost of goods and services: An input — output approach. Ph.D. Dissertation. Milano, Italy: Politecnico di Milano.

[48] Çengel, Y.A., Boles, M.A., Kanoglu, M. (2019). Thermodynamics: An Engineering Approach. Ninth edition. New York, NY: McGraw-Hill Education.

[49] PRé, various authors. (2019). SimaPro Database Manual-Methods Library. https://simapro.com/wpcontent/uploads/2019/02/DatabaseManualMethods.pdf.

[50] Tao, F., Zuo, Y., Xu, L.D., Lv, L., Zhang, L. (2014). Internet of Things and BOM-Based Life Cycle Assessment of Energy-Saving and Emission-Reduction of Products. IEEE Transactions on Industrial Informatics, 10(2): $1252-1261$ https://doi.org/10.1109/TII.2014.2306771

[51] Chen, X., Li, C., Tang, Y., Xiao, Q. (2018). An Internet of Things based energy efficiency monitoring and management system for machining workshop. Journal of Cleaner Production, 199: 957-968. https://doi.org/10.1016/j.jclepro.2018.07.211

[52] Lee, J., Bagheri, B., Kao, H.A. (2015). A Cyber-Physical Systems architecture for Industry 4.0-based manufacturing systems. Manufacturing Letters, 3: 18-23. https://doi.org/10.1016/j.mfglet.2014.12.001

\section{NOMENCLATURE}

$\overline{\mathrm{e}}$

$\mathrm{Ex}$

$\mathrm{H}$

$\overline{\mathrm{h}}$

$\mathrm{m}$

n

r

Q

$\overline{\mathrm{S}}$

$\mathrm{T}$

W

\section{Greek symbols}

\section{Subscripts and Superscripts}

c number of total enthalpy flows

ch chemical

d number of total workflows

e equilibrium

g general

i

$\mathrm{k}$

loss

n

O

$\mathrm{p}$

th

$\mathrm{y}$ əxergetic efficiency, dimensionless

specific heat, $\mathrm{J} \cdot \mathrm{kg}^{-1} \cdot \mathrm{K}^{-1}$

exergy, J.kg

enthalpy flow rate, ${\mathrm{J} . \mathrm{s}^{-1}}^{-1}$

specific enthalpy, ${\mathrm{J} . \mathrm{kg}^{-1}}^{-1}$

mass flow rate, kg. $\mathrm{s}^{-1}$

heat transfer flow rate, ${\mathrm{J} . \mathrm{s}^{-1}}^{-1}$

specific entropy, J.kg

workflow rate, J.s ${ }^{-1}$

state point at the inlet of system/sub-system number of total mass flows

flow rate loss during the sub-processes

net use

state point at the outlet of system/sub-system

number of total heat transfer flows

thermal

number of energy flows for CexD 